Kalpa Publications in Engineering
Volume 4, 2022, Pages 73-89
Proceedings of International Sym-
posium on Applied Science 2021

\title{
Analysis of Thin Wall Structures for Energy Absorption Applications by ABAQUS
}

\author{
Cong Hoa $\mathrm{Vu}{ }^{1,2^{*}}$, Thi Hieu Thao Le ${ }^{1,2}$ and Phuoc Khanh Huy Nguyen ${ }^{1,2}$ \\ ${ }^{1}$ Department of Engineering Mechanics, Faculty of Applied Sciences, Ho Chi Minh City \\ University of Technology, 268 Ly Thuong Kiet Street, District 10, Ho Chi Minh City, Vietnam \\ ${ }^{2}$ Vietnam National University Ho Chi Minh City, Linh Trung Ward, Thu Duc District, Ho Chi \\ Minh City, Vietnam. \\ vuconghoa@hcmut.edu.vn, thao.le03111999@hcmut.edu.vn, \\ huy. nguyen0801@hcmut.edu.vn
}

\begin{abstract}
Crash-dynamics research has always concentrated significantly in the safety, survivability of passengers in a car crash. To identify the capability of energy absorption of a crash box, a thin-walled structure will be modeled and simulated by ABAQUS software. Investigate the influence of material, cross-sectional, thickness factors on the energy absorption capacity of the tube, using MCDM - Multi-Criteria Decision-Making to get the best option and testing the improvement while filling the tube with Foam material. In this study, beside the cross-sectional, aluminum alloys and steel materials and thickness are factors that influence the energy absorption evaluation criteria, the foam material with difference density are surveyed to compare effectiveness between the foam-filled and hollow crashboxes. The results show that the folds of the foam-filled tube after deformation along the compressive direction will be more continuous and stable. More, the higher foam density, the greater the energy absorption. This prevents the crashbox from deviating from the direction of the force, help directing the collapse of the tube, thereby improving energy absorption without significantly increasing the weight of the structure.
\end{abstract}

\section{Introduction}

In the process of participating in traffic, human life is extremely important. Therefore, ensuring safety and protecting users is an issue that any car manufacturer places a top priority on. Seat belts, airbags and warning reminders are safety protection systems for the driver inside the vehicle and are constantly being researched and developed.

${ }^{*}$ Corresponding author

T.T. Truong, T.N. Tran, T.N. Nguyen and Q.K. Le (eds.), ISAS 2021 (Kalpa Publications in Engineering, vol. 4), pp. $73-89$ 
But they're not enough to maximize the ability to protect the driver. Considering the car is moving when a collision occurs, the car immediately slows down but the driver is still subject to inertia to continue moving and only stops when it collides with the steering wheel or the dashboard. At the same time, the reaction force in the collision will be transmitted to the driver, so the seat belts and airbags will not be able to support the driver. Therefore, the manufacturer is also interested in creating "impulse absorption zones". During the mid-twentieth century, automakers believed that the stiffer the chassis, the safer the vehicle, but in fact it has been proven that there are injuries when the driver is involved in an accident due to the external impact force transmitted through the chassis. stiffness and impact on the driver. Today, car manufacturers will use materials that are highly deformable to absorb the force, redirecting the force away from the seat; metal materials with low stiffness, allowing for a lot of deformation are distributed mainly in the front frame of the car for maximum energy absorption, stiffer and higher thickness materials will be distributed in part of the frame doors, lid, luggage compartment and super-hard materials will be prioritized for use in the cabin - which is responsible for protecting occupants, combined with seat belts and airbags.

The crash box is one of the important energy-absorbing structures in the front bumper of the vehicle, it helps reducing the impact on other parts in the vehicle, increasing deceleration time and safety for the driver so it is designed and manufactured with great care, constantly improved to achieve the best response in the collision.

The analysis investigates the behavior of the crash box when it collides with an object that is considered absolutely rigid, with changes in cross-sectional, material, thickness, thereby choosing the best option in terms of absorption capacity. The evaluations are all through the criteria of Specific Energy Absorption (SEA), maximum force ratio and average force (CFE - Crush Force Efficiency). Then consider the ability to absorb energy when filling the tube with foam material.

This study was broken up into three phases. In the first phase, four models of crash box with square and circular section, are referenced from the model of author Hung Anh Ly et al. [4] to simulate by ABAQUS. In the second phase, three different thin walled tubular cross sectional profiles were selected (circular, square, hexagonal). The influence of changing section, material and thickness is studied. There are a total of 18 options ( 3 sections, 2 materials, 3 thicknesses). The best alternative is chosen by the complex proportional assessment method (COPRAS). In final phase, the best alternative was enhanced of the crash performance by the addition of foam materials.

\section{Methodology}

\subsection{Energy absorption characteristics}

Energy absorption, is defined as an integration of a load-displacement curve as follows [1]:

$$
E_{a}=\int_{0}^{\delta_{\max }} P(\delta) d \delta
$$

Where $P(\delta)$ is an instaneous crushing load, $\delta_{\max }$ and $\delta$ are the maximum and current attainable crush distance, respectively.

Specific energy absorption (SEA) is a key index representing the amount of energy that can be absorbed per unit mass of a structure, SEA can be calculated as demonstrated in Eq.2 [1]:

$$
S E A=\frac{E_{A}}{m}
$$

where $m$ is the mass of the tube.

The mean crushing load can be determined from Eq. 3 [1]: 


$$
P_{\text {mean }}=\frac{1}{\delta} \int_{0}^{\delta} P(\delta) d \delta
$$

The mean crushing load is an indicator of energy absorbing capability of a structure when compared to the axial displacement required to absorb the energy. For thin-walled structures, the load generally fluctuates throughout the crushing process and the highest initial load point is the initial peak load. The maximum peak load is used for initiating collapse and begin the energy absorption process.

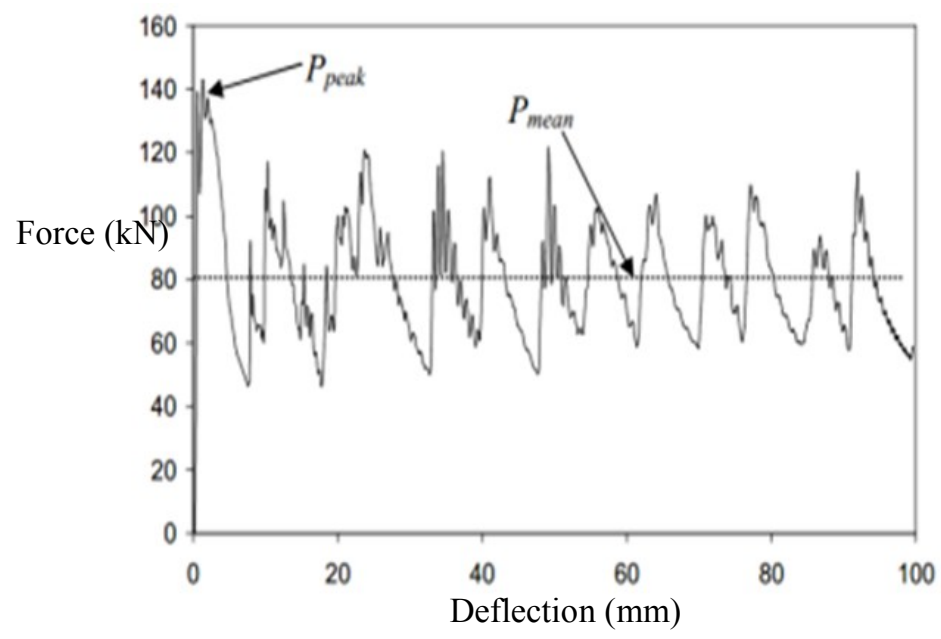

Figure 1: Typical force - deflection diagram

\subsection{Material properties}

There are two types of material used in this study: alloy (Mild Steel RSt37 [2], Aluminum AA6061-T6 [3]) and Polyurethane Foam (F105 [4], F60 [5]).

- Alloy materials

The mechanical properties of Mild Steel RSt37: density $\rho=7830 \mathrm{~kg} / \mathrm{m}^{3}$, Young's Modulus $E=200 \mathrm{GPa}$, initial yield stress $\sigma_{0}=251 \mathrm{MPa}$, ultimate stress $\sigma_{u}=339 \mathrm{MPa}$, Poisson's ratio $v=0.3$, power law exponent $n=0.12$, coefficients of Cowper and Symonds's constitutive equation $D=6844 s^{-1}$ and $q=3.91$.

The mechanical properties of Aluminum AA6061-T6: density $\rho=2700 \mathrm{~kg} / \mathrm{m}^{3}$, Young's Modulus $E=68.9 \mathrm{GPa}$, initial yield stress $\sigma_{0}=276 \mathrm{MPa}$, ultimate stress $\sigma_{u}=350 \mathrm{MPa}$, Poisson's ratio $v=0.33$. 


\section{- Foam materials}

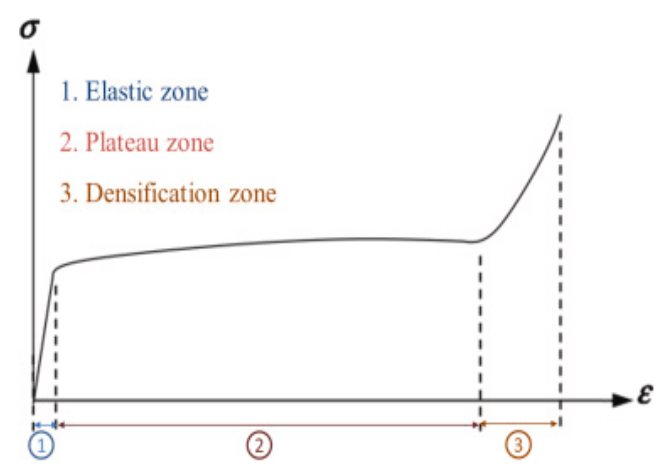

Figure 2: A typical stress-strain curve for foam materials [6]

The mechanical response of foam material depends upon the cell microstructure including cell size and cell topology, properties of the bulk material, and the relative density of the foam material. The relative density of the foam material $\rho^{*}$ is given by [6]:

$$
\rho^{*}=\frac{\rho_{B}}{\rho}
$$

Where $\rho_{B}$ and $\rho$ are the densities of the bulk material associated with cell wall and foam respectively.

Generally, the foam material with greater relative density shows greater mechanical strength and this can be attributed to the higher bulk material within the foam.

The most common mechanical properties of the foam materials are the plateau stress $\sigma_{P}$, elastic modulus $E$, yield point, and the densification strain.

The plateau stress $\sigma_{P}$ is a function of the foam's relative density and it is given by [6]:

$$
\sigma_{P}=C\left(\rho^{*}\right)^{m}
$$

where coefficients $\mathrm{C}$ and $\mathrm{m}$ are material parameters.

The mechanical properties of polyurethane foam F105 [4]: density $\rho=150 \mathrm{~kg} / \mathrm{m}^{3}$, Young's Modulus $E=3 G P a$, Poisson's ratio $v=0$, compression yield stress ratio is 1.1, plastic's Poisson ratio is 0 .

The mechanical properties of polyurethane foam F60 [5]: density $\rho=60 \mathrm{~kg} / \mathrm{m}^{3}$, Young's Modulus $E=7.5 \mathrm{GPa}$, Poisson's ratio $v=0$, compression yield stress ratio is 1.0, plastic's Poisson ratio is 0 .

\subsection{The complex proportional assessment method (COPRAS)}

Multi-criteria decision making (MCDM) is an implicational field that concerns with designing and selecting the best alternative among a finite set of alternatives based on a finite set of criteria [7]. MCDM is divided into multi-objective decision making and multi-attribute decision making (MADM). For the MCDM process, the complex proportional assessment (COPRAS) method was chosen. The COPRAS method introduced by Zavadskas et al. (1994) is an MADM technique. The algorithm of the COPRAS method consists of the steps introduced below [7]: 
Step 1: Select the available set of the most important attributes describing the alternatives.

Step 2: Create the decision-making matrix (X)

$$
\begin{aligned}
& C_{1} \quad C_{2} \quad \ldots
\end{aligned}
$$

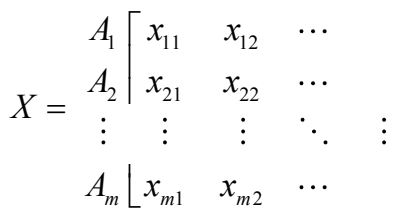

Where $x_{i j}$ is the performance value of the $i t h$ alternative on the $j$ th criterion, $\mathrm{m}$ is the number of alternatives (design concepts) compared and $\mathrm{n}$ is the number of criteria. The entry $x_{i j}$ represents the absolute value for each criteria and $\sum x_{i j}$ is summation for number of positive decisions. However, most design criteria are not in the same dimensions or units. To solve this problem, decision-making matrix $(\mathrm{X})$ was converted to non-dimensionalized matrix $(\mathrm{R})$.

Step 3: Create the normalize decision matrix (R)

$$
R=\left[\begin{array}{cccc}
r_{11} & r_{12} & \cdots \\
r_{21} & r_{22} & \cdots & \\
\vdots & \vdots & \ddots & \vdots \\
r_{m 1} & r_{m 2} & \cdots &
\end{array}\right.
$$

Where $r_{i j}=\frac{x_{i j}}{\sum_{i=1}^{m} x_{i j}}$

Step 4: Determine the weights of attributes $w_{j}$

There are many ways to determine the weights. The following method can be used [1]:

Compare two criteria at a time. Total comparison sets $(\mathrm{N})$ are equal to $N=\frac{n(n-1)}{2}$, where $\mathrm{n}$ is the number of selection criteria.

Amongst the two criteria being selected, the criterion which is more important is given a score of 3 and which is least important is given a score of 1 . If both criteria are of equal importance, a score of 2 is given. We can do the same for all other criteria.

Step 5: Create the weighted normalized decision matrix (D)

Weighted normalized decision matrix (D) was calculated as below:

$$
D=\left[\begin{array}{ccccccccc}
y_{11} & y_{12} & \cdots & & & & \cdots & & \\
y_{21} & y_{22} & \cdots & & & & \ldots & & \\
\vdots & \vdots & \ddots & \vdots & \vdots & \vdots & \ddots & \vdots & \vdots \\
y_{m 1} & y_{m 2} & \cdots & & & & \ldots & &
\end{array}\right.
$$

Step 6: Sum up attribute values where higher values are more preferable (beneficial attributes)

$$
S_{+i}=\sum_{j=1}^{n} y_{+i j}
$$

Step 7: Sum up attributes values where lower values are more preferable (non - beneficial attributes) 


$$
S_{-i}=\sum_{j=1}^{n} y_{-i j}
$$

Step 8: Calculate the relative weight of each alternative

The priorities of the design concepts are calculated based on the notion of relative significance $\left(Q_{i}\right.$ ) :

$$
Q_{i}=S_{+i}+\frac{S_{-\min } \sum_{i=1}^{m} S_{-i}}{S_{-i}\left(S_{-\min } / S_{-i}\right)}
$$

The greater the value of $Q_{i}$, the higher is the priority of the design concept. The design concept with the maximum relative significance $Q_{\max }$ is the best choice for the concept selection decision.

\subsection{Finite Element Modeling}

The impactor was modeled using solid rigid elements and was only permitted to displace in vertical axis. Impact loading was given by using an impactor which moved downward with a velocity of $8 \mathrm{~m} / \mathrm{s}$. Self-contact between the tube walls during collapse, and surface-to-surface contact between each rigid surface and the tube were defined using the finite sliding "penalty" based contact algorithm with contact pairs and "hard" contact. The finite element model of the section are shown in Figure 3. The Belytschko-Tsay shell elements were used to model column wall with mesh size of $5 \times 5 \mathrm{~mm}$. The nodes in the lowest cross section of the column were fixed.

- Finite Element Model Verification

Dimensions of the damper, material (Mild Steel RSt37) and method of setting up the problem are referenced from the model of author Hung Anh Ly et al. [2].
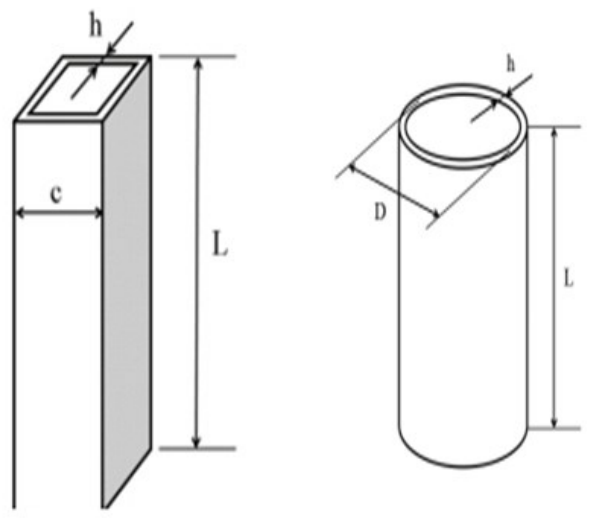

Figure 3: Model of square and circular tubes [2]

\begin{tabular}{lrrrrr}
\hline Dimension of square tubes & $\mathrm{c}$ & $\mathrm{h}$ & $\mathrm{L}$ & $\mathrm{M}$ & $\mathrm{V}$ \\
$\mathrm{mm}$ & $\mathrm{mm}$ & $\mathrm{mm}$ & $\mathrm{m} / \mathrm{s}$ \\
\hline & & & & & \\
\hline Model 1 & 30 & 1 & 240 & 50 & 8 \\
Model 2 & 30 & 0.75 & 300 & 35 & 8 \\
\hline
\end{tabular}

Table 1. Dimensions of square tubes 


\begin{tabular}{lrrrrr}
\hline Dimension of circular tubes & $\mathrm{c}$ & $\mathrm{h}$ & $\mathrm{L}$ & $\mathrm{M}$ & $\mathrm{V}$ \\
& $\mathrm{mm}$ & $\mathrm{mm}$ & $\mathrm{mm}$ & $\mathrm{kg}$. & $\mathrm{m} / \mathrm{s}$ \\
\hline Model 3 & 60 & 1.3 & 150 & 80 & 8 \\
Model 4 & 40 & 1 & 150 & 50 & 8 \\
\hline
\end{tabular}

Table 2. Dimensions of circular tubes

- Finite Element Model With Different Factors

Cross-sectional, material and thickness are factors influence the energy absorption evaluation criteria. In this part, 18 options will be modeled and using MCDM to choose the best option.

\begin{tabular}{lrrr}
\hline $\begin{array}{l}\text { Cross- } \\
\text { sectional }\end{array}$ & Square (S) & Circular (C) & Hexagon (H) \\
\hline Dimension & $75 \mathrm{~mm} \times 75 \mathrm{~mm}$ & $\mathrm{D}=95.5 \mathrm{~mm}$ & $50 \mathrm{~mm} \times 6$ \\
Thickness & $1 \mathrm{~mm}(\mathrm{~T} 1)$ & $0.75 \mathrm{~mm}(\mathrm{~T} 2)$ & $1.25 \mathrm{~mm}$ (T3) \\
Length & & $\mathrm{L}=350 \mathrm{~mm}$ & \\
\hline
\end{tabular}

Table 3: Dimension of crash-boxes

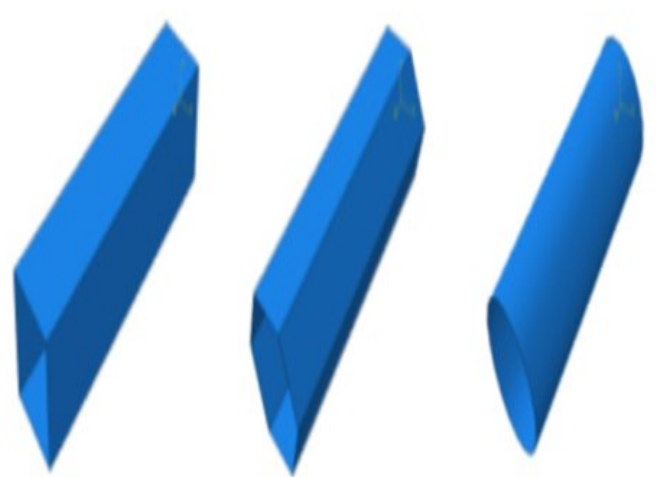

Figure 4: Models of crashbox with different cross sections (square, circular, hexagonal)

\section{- Finite Element Model with Foam-filled}

The finite element model of the section is shown in Figure 5. The Belytschko-Tsay shell elements were used to model column wall with mesh size of $5 \times 5 \mathrm{~mm}$ and $3 \times 3 \mathrm{~mm}$ for Foam-filled. Self-contact between the tube walls during collapse, and surface-to-surface contact between each rigid surface, the tube and foam-filled inside were defined using the finite sliding "penalty" based contact algorithm with contact pairs and "hard" contact. 


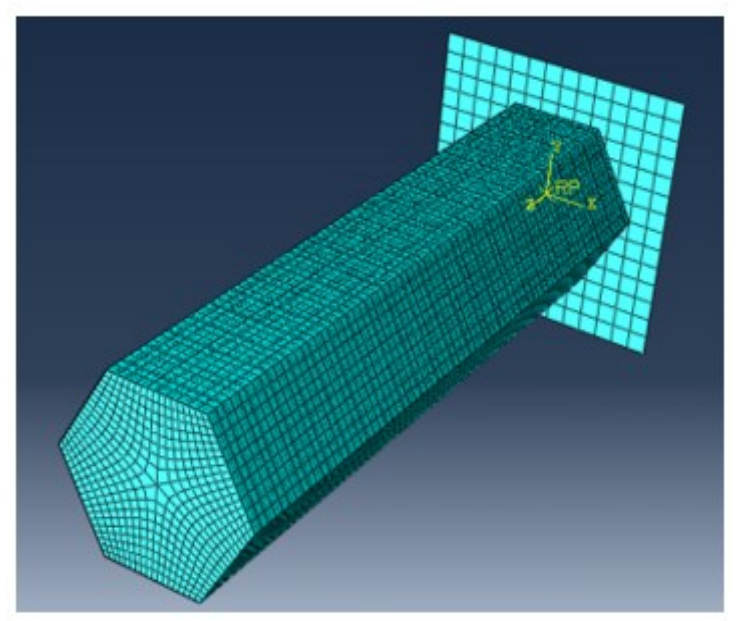

Figure 5: Finite element model of foam-filled crash-box

\begin{tabular}{lrr}
\hline Material & Crash box AA6061-T6 & Polyruethane Foam \\
\hline Cross section & Hexagon & Hexagon \\
Dimension & $50 \mathrm{~mm}$ x 6 & $49.625 \mathrm{~mm}$ x 6 \\
Thickness & $0.75 \mathrm{~mm}$ & \\
\end{tabular}

Table 4: Geometrical details of foam-filled crashbox

\section{Results and discussion}

- Finite Element Model Verification 


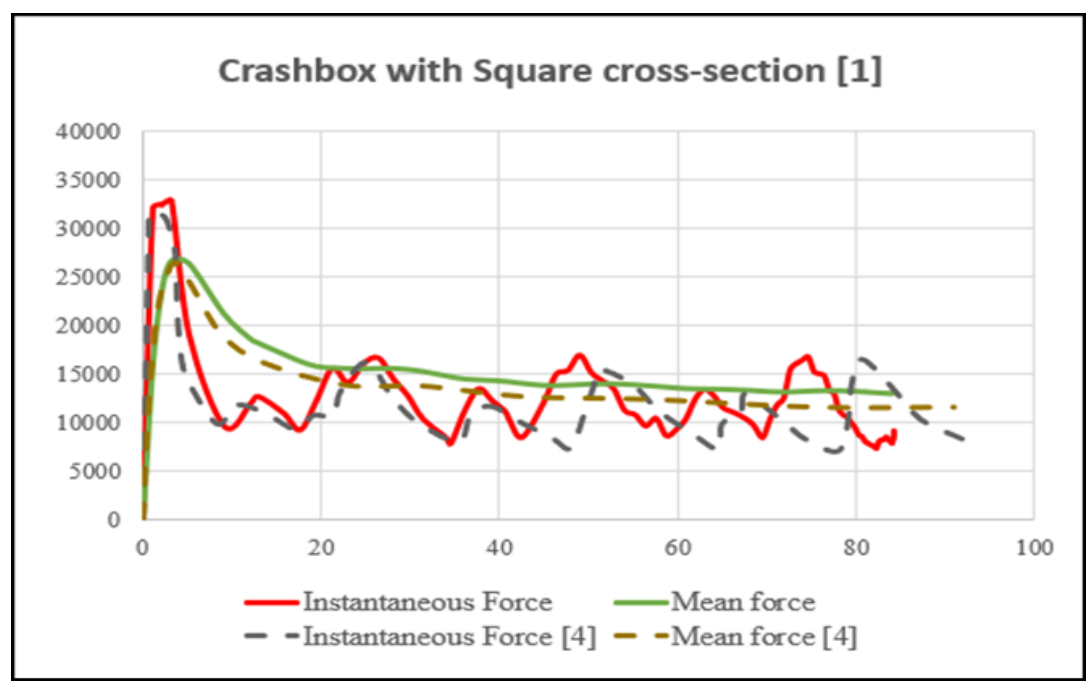

Figure 6: Instantaneous load and mean load of model (1)

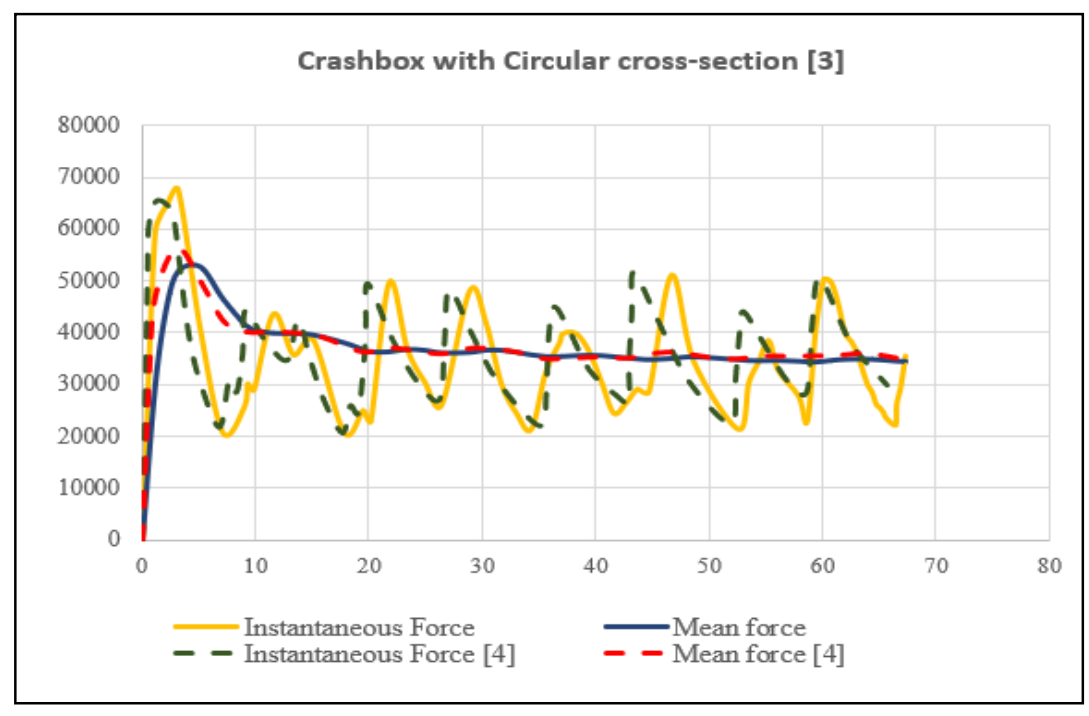

Figure 7: Instantaneous load and mean load of model (3) 


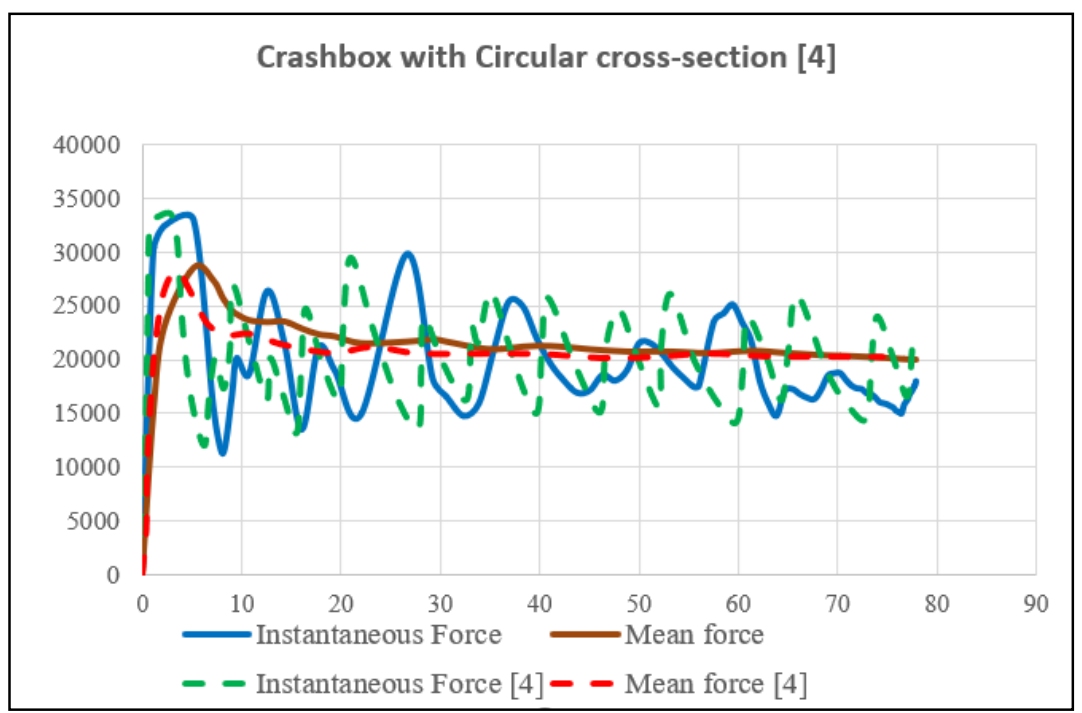

Figure 8: Instantaneous load and mean load of model (4)

This following table compares peak force and mean force of current models with models from [2]. The table below compares the mean force calculated from the simulation results and the results of [2], along with the approximate calculated data by analytical method in the references [8], [9] and [10].

\begin{tabular}{lrrrrr}
\hline Results & Mean force & Mean force & Error & Mean force & Error \\
& & {$[4]$} & & {$[5]$} & $\%$ \\
\hline Model 1 & $k N$ & $k N$ & $\%$ & $k N$ & $\% .21$ \\
Model 2 & 12.96 & 11.35 & 14.2 & 13.53 & 7.2 \\
\hline
\end{tabular}

Table 5: Mean force of square tubes comparison with model [2] and analytical method result in [8]

\begin{tabular}{lrrrrrrr|}
\hline Results & Mean force & Mean force & Error & Mean force & Error & Mean force & Error \\
& & {$[4]$} & & {$[6]$} & & {$[7]$} & \\
& $k N$ & $k N$ & $\%$ & $k N$ & $\%$ & $k N$ & $\%$ \\
\hline Model 3 & 34.55 & 34.93 & 1.1 & 32.04 & 7.8 & 33.79 & 2.2 \\
Model 4 & 20.02 & 20.28 & 1.3 & 18.38 & 8.9 & 19.39 & 3.2 \\
\hline
\end{tabular}

Table 6: Mean force of square tubes comparison with model [2] and analytical method result in [9] and [10]

Based on the above data table, it is found that the results of the current model are relatively similar to the research results of author Hung Anh Ly et al. [4] and the approximate calculation results by analytical method in [5], [6], [7]. This proves that the simulation and calculation methods are correct, which is the basis for the development of the following parts. 
- Finite Element Model With Different Factors

\begin{tabular}{ccrrr}
\hline No. & Options & EA & SEA & CFE \\
\hline 1 & SST1 & $29.6 .10^{5}$ & $36.07 .10^{5}$ & 0.314 \\
2 & CST1 & $30.04 .10^{5}$ & $36.54 .10^{5}$ & 0.405 \\
3 & HST1 & $30.16 .10^{5}$ & $36.69 .10^{5}$ & 0.707 \\
4 & SAT1 & $29.6 .10^{5}$ & $104.24 .10^{5}$ & 0.565 \\
5 & CAT01 & $27.4 .10^{5}$ & $96.65 .10^{5}$ & 0.560 \\
6 & HAT01 & $32.2 .10^{5}$ & $113.46 .10^{5}$ & 0.576 \\
7 & SST2 & $30.2 .10^{5}$ & $49.04 .10^{5}$ & 0.317 \\
8 & CST2 & $30.69 .10^{5}$ & $49.74 .10^{5}$ & 0.427 \\
9 & HST2 & $30.8 .10^{5}$ & $49.91 .10^{5}$ & 0.589 \\
10 & SAT2 & $27.9 .10^{5}$ & $131.04 .10^{5}$ & 0.495 \\
11 & CAT2 & $30.3 .10^{5}$ & $142.26 .10^{5}$ & 0.294 \\
12 & HAT2 & $30.52 .10^{5}$ & $143.33 .10^{5}$ & 0.504 \\
13 & SST3 & $28.63 .10^{5}$ & $32.14 .10^{5}$ & 0.419 \\
14 & CST3 & $28.91 .10^{5}$ & $28.07 .10^{5}$ & 0.527 \\
15 & HAT3 & $31.24 .10^{5}$ & $30.33 .10^{5}$ & 0.565 \\
16 & SAT3 & $26.42 .10^{5}$ & $86.07 .10^{5}$ & 0.649 \\
17 & CAT3 & $31.05 .10^{5}$ & $87.71 .10^{5}$ & 0.486 \\
18 & HAT3 & $27.21 .10^{5}$ & $76.86 .10^{5}$ & 0.593 \\
\hline
\end{tabular}

Table 7: Data of EA, SEA, CFE parameter of the above 18 options

Using COPRAS method with 4 criteria's: SEA, CFE, Price and Manufacture to get the best option not only have a high energy absorption capacity but also consistent with manufacturer's requirements.

\begin{tabular}{cccccccccc}
\hline Criteria & \multicolumn{7}{c}{ Number of comparison } \\
\hline SEA & 1 & 2 & 3 & 4 & 5 & 6 & Total & Weightage \\
CFE & 3 & 3 & 3 & & & & 9 & 0.375 \\
Price & 1 & & & 3 & 3 & & 7 & 0.291 \\
Manufacture & & 1 & & 1 & & 2 & 4 & 0.167 \\
& & & 1 & & 1 & 2 & 4 & 0.167 \\
& & & & & & \\
\end{tabular}

Table 8: Weightage of criteria's 


\begin{tabular}{rrrrr}
\hline No. & S+ & S- & S-min/S- & Q \\
\hline 1 & 0.020348549 & 0.0153439 & 11.364 & 0.0206 \\
2 & 0.023442316 & 0.0082109 & 21.236 & 0.0239 \\
3 & 0.0332839 & 0.011919 & 14.629 & 0.0336 \\
4 & 0.047706882 & 0.0079375 & 21.967 & 0.0482 \\
5 & 0.045395824 & 0.0079366 & 21.97 & 0.0459 \\
6 & 0.050668223 & 0.0119048 & 14.647 & 0.051 \\
7 & 0.024115778 & 0.0079365 & 21.97 & 0.0246 \\
8 & 0.027882015 & 0.0079365 & 21.97 & 0.0284 \\
9 & 0.03317874 & 0.0119048 & 14.647 & 0.0335 \\
10 & 0.052986658 & 0.0079365 & 21.97 & 0.0535 \\
11 & 0.049657514 & 0.0079365 & 21.97 & 0.0502 \\
12 & 0.056757433 & 0.0119048 & 14.647 & 0.0571 \\
13 & 0.022634509 & 0.0079365 & 21.97 & 0.0231 \\
14 & 0.02501644 & 0.0079365 & 21.97 & 0.0255 \\
15 & 0.026869847 & 0.0119048 & 14.647 & 0.0272 \\
16 & 0.045325364 & 0.0079365 & 21.97 & 0.0458 \\
17 & 0.040478204 & 0.0079365 & 21.97 & 0.041 \\
18 & 0.04091847 & 0.0119048 & 14.647 & 0.0413 \\
\hline
\end{tabular}

Table 9: The relative weight of each alternative

Option 12 has the largest $\mathrm{Q}$, so it will be the most optimal to meet the given criteria. This option applies to the crash box with hexagonal cross section, aluminum material AA6061 - T6 and has a wall thickness of $0.75 \mathrm{~mm}$.

- Finite Element Model With Foam-filled

\begin{tabular}{lrrr}
\hline & EA & SEA & CFE \\
& $10^{5}$ & $10^{5}$ & \\
\hline HAT2 & 30.52 & 143.33 & 0.504 \\
HAT2F60 & 30.84 & 145.78 & 0.61 \\
HAT2F105 & 31.07 & 146.02 & 0.641 \\
\hline
\end{tabular}

Table 10: Result of characteristics coefficients of crash-box models 

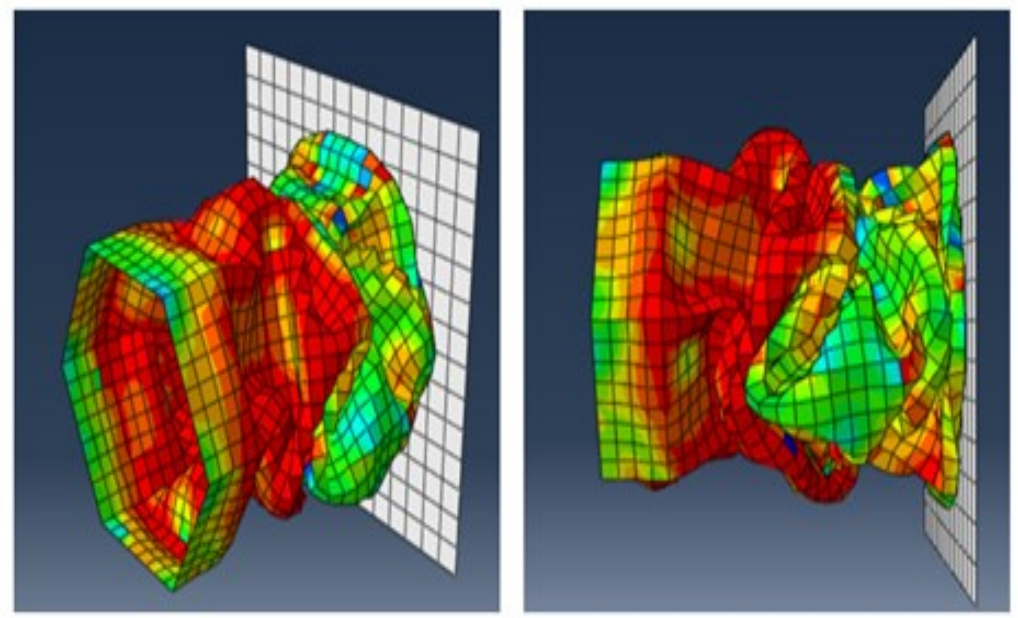

Figure 10: Crash box without foam
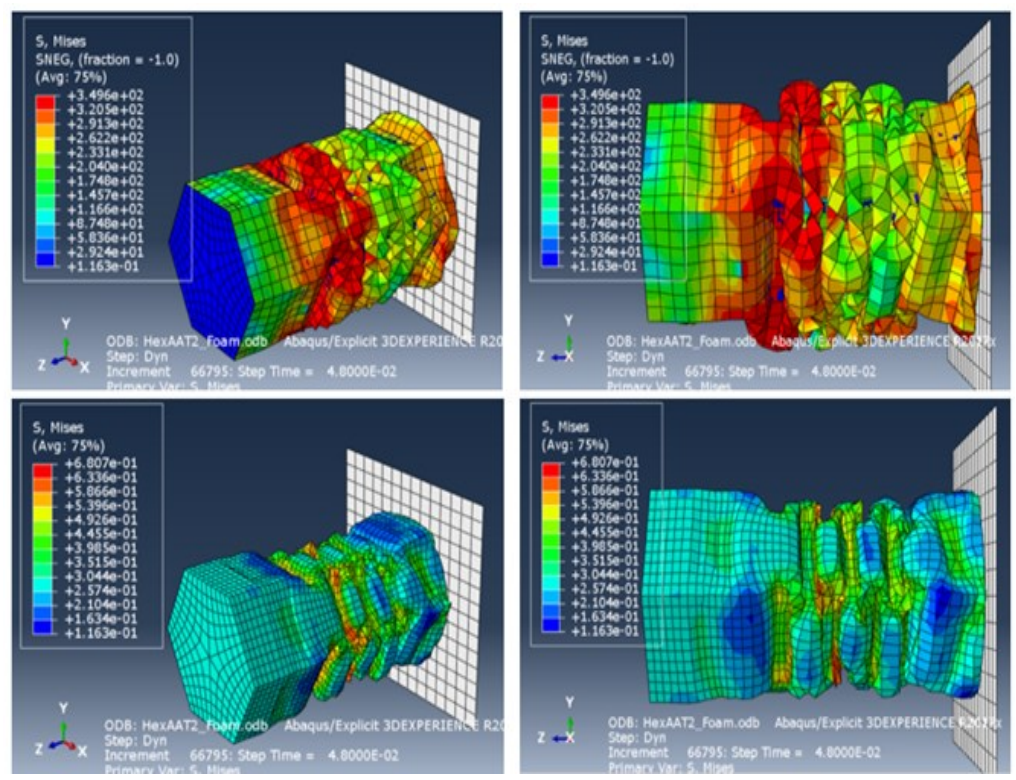

Figure 9: Crash box with foam $105 \mathrm{~kg} / \mathrm{m}^{3}$ 

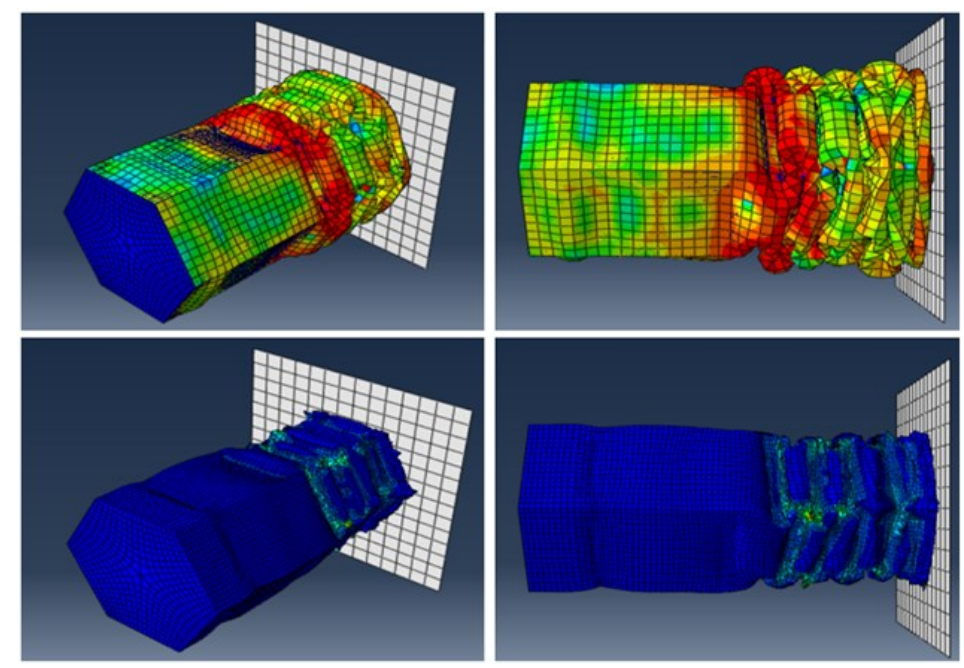

Figure 12: Crash box with foam $60 \mathrm{~kg} / \mathrm{m}^{3}$

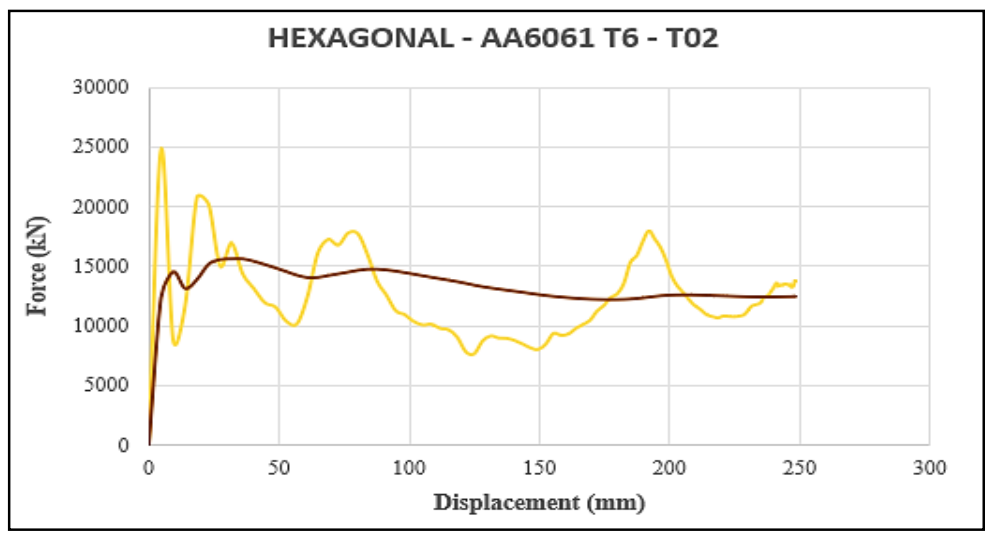

Figure 11: Force - displacement diagrams of model crashbox without foam

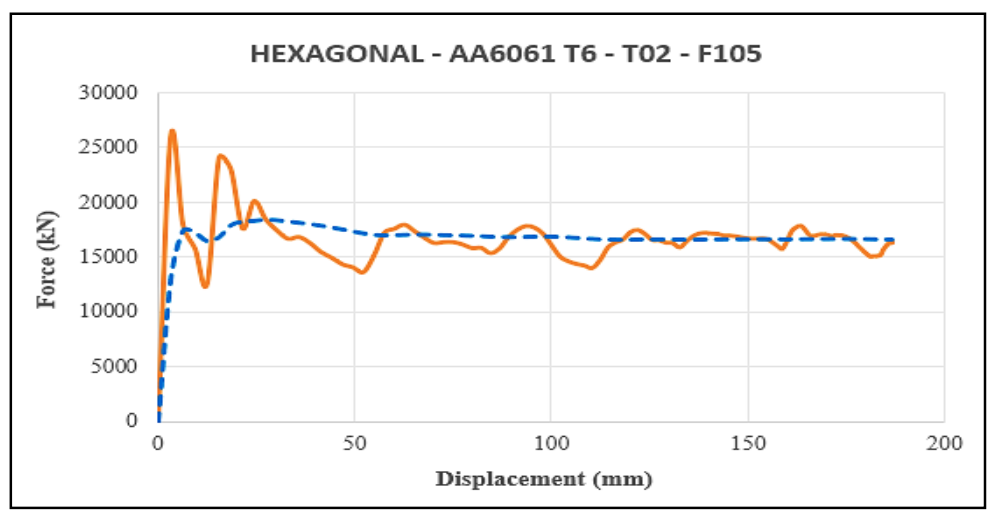

Figure 13. Force - displacement diagrams of model crashbox with foam F105 


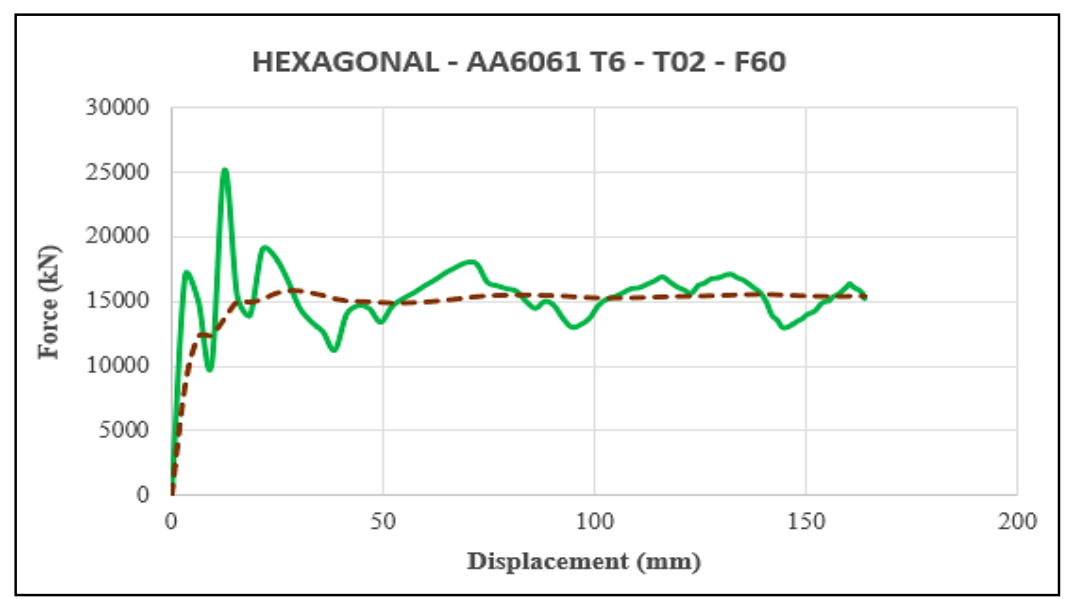

Figure 14: Force - displacement diagrams of model crashbox with foam F60

Comparing the results of stress and force - displacement between the cases, we can see that tube filled Foam $105 \mathrm{~kg} / \mathrm{m}^{3}$ (HAT2F105) has formed the most folds and these folds are more constant and smoother, also the value of peak force and it's CFE is much larger than the other two cases, and the tube filled Foam $60 \mathrm{~kg} / \mathrm{m}^{3}$ is higher than the hollow tube.

The characteristic coefficients for the energy absorption of the foam-filled tube are always higher than the hollow one, and the tube filled foam with a density of $105 \mathrm{~kg} / \mathrm{m}^{3}$ are always higher than the one with density $60 \mathrm{~kg} / \mathrm{m}^{3}$, which proves that the foam-filled tube has better energy absorption capacity than the hollow one, and the foam absorption capacity will be higher when the foam density is higher.

\section{Conclusion}

When a collision occurs, the hollow thin-walled structure crashbox will be subjected to a large compressive force in a very short time, which will easily cause deformations away from the direction of the original applied force, forming unstable folds. This greatly affects the ability of the shock absorber to absorb energy.

When performing the method of inserting foam into the hollow tube, we find that the tube deforms along the compressive direction and creates more continuous and stable folds. For foam-filled with higher density, the energy absorption capacity is higher, and the folds tend to bulge out more. This is because foam materials have a large plateau stress region in the stress-strain curve under compressive loads, which allows them to undergo increasing strain but remain a constant level of low stress, and this stress region changes only when there is a change in foam density. Therefore, when the tube begins to plastically deform to create folds, the foam-filled inside will also deform, move along the wall of the tube, evenly distribute and fill the sides, making the folds become continuous and stable. The higher foam density, the greater the energy absorption, when compressed, the folds will be filled more, causing the folds to swell more. This prevents the crashbox from deviating from the direction of the force, help directing the collapse of the tube, thereby improving energy absorption without significantly increasing the weight of the structure. 


\section{Conflicts of Interest}

The authors declare no conflicts of interest.

\section{Acknowledgment}

We acknowledge the support of time and facilities from Ho Chi Minh City University of Technology (HCMUT) - VNU-HCM for this study.

\section{References}

[1] F. Tarlochan, F. Samer, A.M.S. Hamouda, S. Ramesh, Karam Khalid, "Design of thin wall structures for energy absorption applications: Enhancement of crashworthiness due to axial and oblique impact forces". Thin-Walled Structures 71, pp. 7-17,2013.

[2] Hung Anh Ly, Thinh Thai Quang, "Numerical investigation of circular and square tubes subjected to low velocity impact load", International Journal of Mechanical Engineering and Applications, 2015.

[3] Nassier A. Nassir, Ayad K. Hassan. "Numerical response of aluminium plate (6061-T6) under dynamic loadings". 2nd International Scientific Conference of Engineering Sciences, 2020

[4] Azrol Jailani, "Nonlinear numerical simulation of dynamic energy absorption on unfilled and foam filled cotton fibre/propylene corrugated of tubular structure". Proceedings of the 2nd. International Conference on Arts, Social Sciences \& Technology Penang, Malaysia, 3rd. 5th.. March 2012.

[5] Akbar Othman, Simmathiri Applanaidu, Azrol Jailani, Mohd Zaidi Hamzah. "Numerical studies of crashworthiness behavior on hollow and polyurethane foamfilled mild-steeltapered tubes underdynamic oblique loading". Proceedings of the 2nd. International Conference on Arts, Social Sciences \& Technology Penang, Malaysia, 3rd. - 5th. March 2012.

[6] Ahmad Baroutaji, Arun Arjunan, Abbas Niknejad, TrongNhan Tran, Abdul-Ghani Olabi. "Application of Cellular Material in Crashworthiness Applications: An Overview". Reference Module in Materials Science and Materials Engineering.

[7] Zavadskas, E.K., Kaklauskas, A., \& Sarka, V. "The new method of multicriteria complex proportional assessment of projects". Technological and Economic Development of Economy, 1994.

[8] W. Abramowicz, N. Jones, "Dynamic axial crushing of square tubes," International Journal of Impact Engineering, vol. 2, no. 2, 1984.

[9] W. Abramowicz, N. Jones, "Dynamic axial crushing of circular tubes", International Journal of Impact Engineering, vol. 2, no. 3, 1984.

[10] W. Abramowicz, N. Jones, "Dynamic progressive buckling of circular and square tubes", International Journal of Impact Engineering.

[11] McGregor, L.J.; Meadows, D.J.; Scott, C.E.; Seeds, A.D. "Impact performance of aluminum structures". In: Jones $N$ and WierzbickiT, Structural Crashworthiness and Failure, Elsevier Science Publisher, pp. 385-421, 1993.

[12] Azrol Jailani, "Nonlinear numerical simulation of dynamic energy absorption on unfilled and foam filled cotton fibre/propylene corrugated of tubular structure". Proceedings of the 2nd. 
International Conference on Arts, Social Sciences \& Technology Penang, Malaysia, 3rd. - 5th. March 2012. 